\title{
Locus Coeruleus Stimulation Recruits a Broad Cortical Neuronal Network and Increases Cortical Perfusion
}

\author{
Xavier Toussay, Kaustuv Basu, Baptiste Lacoste, and Edith Hamel \\ Laboratory of Cerebrovascular Research, Montreal Neurological Institute, McGill University, Montréal, Québec, Canada H3A 2B4
}

The locus coeruleus (LC), the main source of brain noradrenalin (NA), modulates cortical activity, cerebral blood flow (CBF), glucose metabolism, and blood- brain barrier permeability. However, the role of the LC-NA system in the regulation of cortical CBF has remained elusive. This rat study shows that similar proportions $(\sim 20 \%)$ of cortical pyramidal cells and GABA interneurons are contacted by LC-NA afferents on their cell soma or proximal dendrites. LC stimulation induced ipsilateral activation (c-Fos upregulation) of pyramidal cells and of a larger proportion $(>36 \%)$ of interneurons that colocalize parvalbumin, somatostatin, or nitric oxide synthase compared with pyramidal cells expressing cyclooxygenase- $2(22 \%, p<0.05)$ or vasoactive intestinal polypeptide-containing interneurons $(16 \%$, $p<0.01$ ). Concurrently, LC stimulation elicited larger ipsilateral compared with contralateral increases in cortical CBF ( 52 vs $31 \%, p<$ 0.01 ). These CBF responses were almost abolished $(-70 \%, p<0.001)$ by cortical NA denervation with DSP-4 [ $N$-(2-chloroethyl)- $N$-ethyl2-bromobenzylamine hydrochloride] and were significantly reduced by $\alpha$ - and $\beta$-adrenoceptor antagonists $(-40 \%, p<0.001$ and $-30 \%, p<0.05$, respectively). Blockade of glutamatergic or GABAergic neurotransmission with NMDA or $\mathrm{GABA}_{\mathrm{A}}$ receptor antagonists potently reduced the LC-induced hyperemic response $(-56 \%, p<0.001$ or $-47 \%, p<0.05)$. Moreover, inhibition of astroglial metabolism $(-35 \%, p<0.01$ ), vasoactive epoxyeicosatrienoic acids (EETs; $-60 \%, p<0.001$ ) synthesis, large-conductance, calcium-operated $(\mathrm{BK},-52 \%, p<0.05)$, and inward-rectifier (Kir, $-40 \%, p<0.05) \mathrm{K}^{+}$channels primarily impaired the hyperemic response. The data demonstrate that LC stimulation recruits a broad network of cortical excitatory and inhibitory neurons resulting in increased cortical activity and that $\mathrm{K}^{+}$fluxes and EET signaling mediate a large part of the hemodynamic response.

\section{Introduction}

The locus coeruleus (LC), a small brainstem nucleus rich in noradrenalin (NA)-containing neurons, provides a widespread innervation to the cerebral cortex (Foote et al., 1983; Berridge and Waterhouse, 2003). Cortical LC-NA afferents have multiple targets that include excitatory pyramidal cells, inhibitory GABA interneurons (Branchereau et al., 1996; Paspalas and Papadopoulos, 1999), astrocytes (Séguéla et al., 1990), and the microvasculature with its associated astrocytic endfeet (Paspalas and Papadopoulos, 1996; Cohen et al., 1997). After LC stimulation, NA release is increased in the cerebral cortex (Florin-Lechner et al., 1996) and cortical neuronal activity is enhanced as assessed by electroencephalogram recordings and behavioral indices of arousal (Berridge and Foote, 1991; Carter et al., 2010). This pathway also activates cortical astrocytes, which display rapid intracellular $\mathrm{Ca}^{2+}$ increases in response to $\mathrm{LC}$ stimulation in vivo

Received July 13, 2012; revised Dec. 17, 2012; accepted Dec. 20, 2012.

Author contributions: X.T. and E.H. designed research; X.T. and K.B. performed research; X.T., K.B., B.L., and E.H. analyzed data; X.T. and E.H. wrote the paper.

This work was supported by Canadian Institutes of Health Research Grant MOP-84209 (E.H.). We thank Dr. Clotilde Lecrux for the training to cerebral blood flow measurements and analysis and Dr. X.-K. Tong for help in the realization of semithin sections.

The authors declare no competing financial interests.

Correspondence should be addressed to Dr. Edith Hamel, Montreal Neurological Institute, McGill University, 3801 University Street, Montréal, Québec, Canada, H3A 2B4. E-mail: edith.hamel@mcgill.ca.

DOI:10.1523/JNEUROSCI.3346-12.2013

Copyright $\odot 2013$ the authors $\quad 0270-6474 / 13 / 333390-12 \$ 15.00 / 0$
(Bekar et al., 2008) or enhanced glucose metabolism after NA application in vitro (Sorg and Magistretti, 1991).

Based on its facilitating role on neuronal and astrocytic activity, LC stimulation would be expected to elicit increases in cortical perfusion, a condition known as neurovascular coupling (NVC) whereby regional increases in neuronal activity are spatially and temporally matched by increases in local cerebral blood flow (CBF). Particularly, increased $\mathrm{Ca}^{2+}$ signaling in astrocytes has been associated with release of vasodilatory astroglial messengers (Koehler et al., 2009; Petzold and Murthy, 2011), dilatation of brain microvessels, and CBF increases (Carmignoto and Gomez-Gonzalo, 2010). Surprisingly, however, global decreases in CBF have mostly been reported after pharmacologic or electrical manipulation of the LC-NA system (Raichle et al., 1975; de la Torre, 1976; Goadsby and Duckworth, 1989). Because a negative NVC response has been linked to reduced neuronal activity and functional inhibition (Shmuel et al., 2006; Schäfer et al., 2012), decreased cortical CBF after LC stimulation appears counterintuitive given that it could deprive active neurons of adequate nutrients. This would also suggest a unique modulation of cortical activity by NA and an unprecedented mismatch between neuronal and hemodynamic responses.

In the present study, we revisited the hemodynamic response to activation of LC-NA system. We identified the neuronal targets of NA afferents together with the cortical circuitry recruited during LC stimulation. Finally, we characterized the purported neuronal, astroglial, or vascular mediators of the resulting alterations in cortical perfusion. Our data demonstrate that stimula- 
tion of the LC activates a broad network of cortical pyramidal cells and interneurons and concomitantly increases cortical perfusion. The hyperemic response virtually disappeared after selective lesioning of the LC-NA system and required activation of $\alpha$ - and $\beta$-adrenoreceptors. In addition, the evoked CBF response to the LC-NA system required the release of glutamate and GABA likely from the recruited subsets of pyramidal cells and interneurons and was primarily mediated by epoxyeicosatrienoic acids (EETs) and potassium $\left(\mathrm{K}^{+}\right)$fluxes through largeconductance, calcium-operated $(\mathrm{BK})$ and inward-rectifier (Kir) $\mathrm{K}^{+}$channels. These findings highlight the crosstalk between neurons, astrocytes and arterioles (Filosa et al., 2006, Cauli and Hamel, 2010, Dunn and Nelson, 2010) in the regulation of the hyperemic response to activation of the LC-NA pathway.

\section{Materials and Methods}

Drugs. Pharmacological compounds were as follows: phentolamine (2-[N(3-hydroxyphenyl)-p-toluidinomethyl]-2-imidazolidine hydrochloride; vehicle saline), propanolol [( \pm )-1-isopropylamino-3-(1-naphthyloxy)-2-propanol hydrochloride; vehicle saline], DSP-4 [N-(2chloroethyl)- $N$-ethyl-2-bromobenzylamine hydrochloride], and phenylephrine $[(R)-(-)-1-(3$-hydroxyphenyl)-2-methylaminoethanol hydrochloride], and barium chloride $\left(\mathrm{BaCl}_{2}\right.$; vehicle saline) were purchased from Sigma-Aldrich. ODQ (1H-[1,2,4] oxadiazolo[4,3a] quinoxalin-1-one; vehicle $0.2 \%$ ethanol in $0.5 \mathrm{M} \mathrm{PBS}$ ) was from Ascent Scientific, and paxilline (vehicle 0.5\% DMSO in $0.5 \mathrm{~m}$ PBS) was from Cayman Chemical. The other compounds were as in our previous studies (Lecrux et al., 2011, 2012).

Animals. Adult male Sprague Dawley rats ( 300 g; Charles River) were used in all experiments. Procedures were approved by the animal ethics committee of the Montreal Neurological Institute and followed the guidelines outlined by the Canadian Council on Animal Care.

Innervation of cortical neurons by LC-NA afferents. The association between NA nerve terminals and cortical pyramidal cells or GABA interneurons in the frontoparietal cortex was evaluated by double immunohistochemistry on semithin sections. Rats were deeply anesthetized with sodium pentobarbital ( $50 \mathrm{mg} / \mathrm{kg}$, i.p.), and their brains were perfusion fixed $[500 \mathrm{ml}$ of ice-cold $4 \%$ paraformaldehyde (PFA) in $0.1 \mathrm{M}$ phosphate buffer, $\mathrm{pH} 7.4$ ] and postfixed by immersion in $4 \%$ PFA ( $2 \mathrm{~h}$, $\left.4^{\circ} \mathrm{C}\right)$. Brains were then cut in $60-\mu \mathrm{m}$-thick coronal sections with a vibratome (Leica). To label NA nerve terminals, sections were first incubated with a mouse anti-dopamine $\beta$-hydroxylase antibody (DBH; 1:2000, Millipore Bioscience Research Reagents), detected with the AB complex (Vectastain ABC kit, Elite PK-6100; Vector Laboratories), and revealed with 3,3'-diaminobenzidine (DAB; brown precipitate; kit SK4100; Vector Laboratories). The cellular targets of these NA terminals were identified by double immunohistochemistry with markers of specific subtypes of pyramidal cells or GABA interneurons and detected with the SG reagent (blue-gray precipitate; SK-4700; Vector Laboratories). Antibodies included goat anti-cyclooxygenase-2 (COX-2; 1:500; Santa Cruz Biotechnology), mouse anti-choline acetyltransferase (ChAT; 2 $\mathrm{mg} / \mathrm{ml}$; kindly provided by Dr. B. K. Hartman, University of Minnesota, $\mathrm{MN}$ ) or anti-parvalbumin (PV; 1:40,000; Sigma-Aldrich), rabbit antisomatostatin (SOM; 1:2000; Peninsula Laboratories) or anti-neuronal nitric oxide synthase (nNOS; 1:10,000; Millipore Bioscience Research Reagents), and guinea pig anti-vasoactive intestinal peptide (VIP; 1:5000; Peninsula Laboratories). Double-immunostained thick sections were then processed for serial semithin sectioning $(2 \mu \mathrm{m})$ of the frontoparietal cortex, as described previously (Vaucher et al., 2000). Sections were mounted on gelatin-coated slides and scanned for visualization and analysis of immunostained material using a MIRAX Scan and Viewer (Carl Zeiss).

Identification of cortical neurons recruited by LC stimulation. The neurochemical nature of recruited (c-Fos positive) cortical neurons was determined using double immunohistochemistry with markers of COX-2 pyramidal cells or specific subtypes of GABA interneurons (PV, SOM, VIP, nNOS), as described previously (Kocharyan et al., 2008; Lecrux et al., 2011). Sections were first immunostained for c-Fos (rabbit anti-cFos, 1:20,000; Calbiochem) and visualized with the SG reagent. All other antibodies were detected in second position with species-specific secondary antibodies (1:200; Vector Laboratories) and visualized with DAB. Sections were observed under a Leitz Aristoplan microscope (Leica) coupled to a digital camera (CoolPix 4500; Nikon), and photomicrographs were edited with the Adobe Photoshop 11 software (Adobe Systems).

Surgery and LC stimulation. Chronic implantation of stimulating monopolar tungsten electrodes ( $100 \mu \mathrm{m}$ tip diameter; FHC) was performed stereotaxically within the LC in isoflurane-anesthetized rats at bregma coordinates anteroposterior (AP) $-11.2 \mathrm{~mm}$, mediolateral (ML) 1.25 $\mathrm{mm}$, and dorsoventral $-5.60 \mathrm{~mm}$ from the brain surface (with an angle at $18.2^{\circ}$, electrodes pointing toward the head). Electrodes were implanted $5 \mathrm{~d}$ before electrical stimulation (experimental day) to avoid nonspecific c-Fos activation (see below). On the experimental day, rats were anesthetized with urethane (1.1 g/kg, i.p.; Sigma) and positioned in a stereotaxic frame (David Kopf Instruments). The LC was stimulated (Isolated Pulse Stimulator model 2100; A-M Systems) in a phasic burst mode to mimic the physiological patterns of LC neuronal discharge induced by a sensory stimulus (Foote et al., 1980; Aston-Jones and Bloom, 1981). Previous antidromic activation studies in rat showed that the thin unmyelinated axons characteristic of LC neurons influenced target cells most effectively with short bursts of high-frequency activity (Aston-Jones et al., 1980). Thus, LC stimulation consisted of 10 bursts of pulses $(100 \mathrm{~Hz}, 0.5 \mathrm{~ms}$ duration) presented at $0.5 \mathrm{~Hz}(1 \mathrm{~s} \mathrm{on} / 1 \mathrm{~s}$ off for a total of $20 \mathrm{~s})$ with a current intensity of $80 \mu \mathrm{A}$. These electrical stimulation paradigms have also been shown to induce NA release in the cortex (Florin-Lechner et al., 1996) and promote synaptically evoked neuronal excitation as seen in conditions of increased alertness or intense arousal that require global activation of the NA pathway (Waterhouse et al., 1998).

CBF measurements. Changes in CBF induced by LC stimulation were measured bilaterally using two laser Doppler flowmetry (LDF) needleshaped probes (Transonic Systems) positioned on corresponding areas of the frontoparietal cortex (bregma coordinates AP $-1.3 \mathrm{~mm}$; $\mathrm{ML} \pm 2$ $\mathrm{mm}$ ), using an intact skull preparation (Kocharyan et al., 2008; Lecrux et al., 2011). Body temperature was maintained at $37^{\circ} \mathrm{C}$ with a heating blanket (Harvard Apparatus), and a catheter filled with heparinized saline was inserted in the femoral artery to monitor mean arterial blood pressure (MAP; PowerLab; ADInstruments), blood gases, and pH (Rapid Lab 348; Bayer, Siemens Healthcare Diagnostics) (Table 1). For induced c-Fos protein detection, rats were removed from the stereotaxic frame at the end of the stimulation and kept in their cage for $2 \mathrm{~h}$ while still anesthetized. Rat brains were then fixed as above, cryoprotected, frozen, and stored $\left(-80^{\circ} \mathrm{C}\right)$ until sectioning as free-floating coronal sections $(25 \mu \mathrm{m}$ thick) on a freezing microtome (SM 2000R; Leica).

Cortical NA denervation. Noradrenergic denervation of the neocortex was performed in rats $(n=6)$ that received a first injection of the selective NA neurotoxin DSP-4 (Jaim-Etcheverry and Zieher, 1980) $(60 \mathrm{mg} / \mathrm{kg}$ in sterile saline, i.p.), followed $7 \mathrm{~d}$ later by a second injection (50 mg/kg, i.p.) (Cohen et al., 1997). Control rats $(n=6)$ received saline. Twelve days later, cortical $\mathrm{CBF}$ responses to LC stimulation were measured, and rats were then perfused and brains processed as above for DBH immunostaining to validate the efficacy of the lesion. As a control for selective LC lesion, the NA innervation of major cerebral arteries from saline- and DSP-4-treated rats was assessed because their perivascular NA fibers originate exclusively from the superior cervical ganglion (Hartman et al., 1972).

Pharmacological investigations. The involvement of $\alpha$ - and $\beta$-adrenoceptors, glutamatergic and GABAergic pathways, as well as of other potential mediators in the CBF response evoked by LC stimulation was investigated by intracisternal injection $(3 \mu \mathrm{l})$ of drugs and their corresponding vehicle. Our goal was to provide evidence for their contribution and not to establish a strict comparison of their respective importance. However, we used optimal concentrations and incubation times for each compound as determined from our previous studies (Kocharyan et al., 2008; Lecrux et al., 2011, 2012) and from pilot experiments $\left(10^{-6}\right.$ to $10^{-3} \mathrm{M}$ concentrations, with CBF responses being measured at 20, 40, and $60 \mathrm{~min}$ after injection). Most drugs were used at a $10^{-4} \mathrm{M}$ concentration except for fluorocitrate $(3 \times$ $\left.10^{-4} \mathrm{M}\right), \mathrm{MK}-801\left(4 \times 10^{-3} \mathrm{M}\right), \mathrm{MS}-\mathrm{PPOH}[\mathrm{N}$-(methylsulfonyl)-2-(2- 
Table 1. Blood parameters during CBF measurements

\begin{tabular}{|c|c|c|c|c|c|c|}
\hline & $\operatorname{MAP}^{a}(\mathrm{mmHg})$ & $\operatorname{MAP}^{b}(\mathrm{mmHg})$ & rCBF (a.u.) & $\mathrm{pCO}_{2}(\mathrm{mmHg})$ & $\mathrm{pO}_{2}(\mathrm{mmHg})$ & $\mathrm{pH}$ \\
\hline \multicolumn{7}{|c|}{ MK-801 $(n=3)$} \\
\hline Baseline & $86.1 \pm 8.5$ & $111.7 \pm 13.9$ & $19.6 \pm 1.0$ & $35.4 \pm 1.8$ & $104.3 \pm 1.7$ & $7.43 \pm 0.04$ \\
\hline Vehicle & $83.1 \pm 9.1$ & $108.1 \pm 14.3$ & $21.3 \pm 1.1$ & $35.7 \pm 1.2$ & $97.8 \pm 4.4$ & $7.43 \pm 0.03$ \\
\hline Drug & $86.7 \pm 12.1$ & $102.6 \pm 14.1$ & $20.9 \pm 2.0$ & $37.8 \pm 4.1$ & $98.1 \pm 3.8$ & $7.45 \pm 0.05$ \\
\hline \multicolumn{7}{|c|}{ MPEP and LY367385 $(n=5)$} \\
\hline Baseline & $92.7 \pm 8.4$ & $124.5 \pm 11.8$ & $22.0 \pm 2.7$ & $40.3 \pm 2.8$ & $97.4 \pm 5.0$ & $7.41 \pm 0.01$ \\
\hline Vehicle & $91.1 \pm 7.2$ & $130.6 \pm 7.9$ & $19.2 \pm 2.0$ & $36.9 \pm 3.2$ & $95.7 \pm 4.5$ & $7.37 \pm 0.07$ \\
\hline Drug & $99.1 \pm 12.4$ & $132.4 \pm 10.8$ & $20.0 \pm 3.2$ & $37.6 \pm 4.4$ & $91.8 \pm 1.7$ & $7.42 \pm 0.01$ \\
\hline \multicolumn{7}{|l|}{$\operatorname{CNQX}(n=4)$} \\
\hline Baseline & $80.5 \pm 16.1$ & $115.9 \pm 9.9$ & $22.1 \pm 4.0$ & $36.2 \pm 1.7$ & $110.9 \pm 2.4$ & $7.40 \pm 0.01$ \\
\hline Vehicle & $81.4 \pm 14.3$ & $112.8 \pm 8.1$ & $24.5 \pm 5.8$ & $33.7 \pm 0.7$ & $106.50 \pm 4.6$ & $7.31 \pm 0.07$ \\
\hline Drug & $87.71 \pm 12.4$ & $116.4 \pm 7.7$ & $26.3 \pm 4.6$ & $38.2 \pm 1.7$ & $100.6 \pm 3.9$ & $7.39 \pm 0.03$ \\
\hline \multicolumn{7}{|c|}{ MS-PPOH $(n=3)$} \\
\hline Baseline & $87.1 \pm 3.5$ & $110.7 \pm 3.0$ & $17.7 \pm 0.8$ & $37.0 \pm 3.4$ & $118.2 \pm 9.5$ & $7.42 \pm 0.01$ \\
\hline Vehicle & $87.2 \pm 6.9$ & $109.2 \pm 2.6$ & $18.1 \pm 0.7$ & $35.6 \pm 2.7$ & $110.3 \pm 2.5$ & $7.42 \pm 0.04$ \\
\hline Drug & $86.6 \pm 5.0$ & $104.0 \pm 4.4$ & $19.8 \pm 1.9$ & $32.2 \pm 7.9$ & $114.5 \pm 4.3$ & $7.33 \pm 0.09$ \\
\hline \multicolumn{7}{|c|}{$14,15-\operatorname{EEZE}(n=5)$} \\
\hline Baseline & $77.1 \pm 15.5$ & $112.1 \pm 17.2$ & $21.0 \pm 4.3$ & $33.4 \pm 2.8$ & $108.4 \pm 5.9$ & $7.39 \pm 0.03$ \\
\hline Vehicle & $80.6 \pm 11.9$ & $108.5 \pm 16.6$ & $20.8 \pm 4.5$ & $33.9 \pm 2.8$ & $99.4 \pm 3.5$ & $7.39 \pm 0.05$ \\
\hline Drug & $79.6 \pm 11.6$ & $109.4 \pm 12.8$ & $21.9 \pm 5.3$ & $33.4 \pm 2.8$ & $101.5 \pm 2.7$ & $7.43 \pm 0.02$ \\
\hline \multicolumn{7}{|c|}{ Fluorocitrate $(n=5)$} \\
\hline Baseline & $95.0 \pm 9.9$ & $122.1 \pm 12.6$ & $20.7 \pm 3.0$ & $35.6 \pm 2.2$ & $103.9 \pm 4.9$ & $7.41 \pm 0.01$ \\
\hline Vehicle & $102.5 \pm 12.2$ & $131.9 \pm 12.3$ & $19.7 \pm 2.0$ & $31.6 \pm 0.8$ & $106.1 \pm 4.4$ & $7.43 \pm 0.02$ \\
\hline Drug & $105.4 \pm 20.1$ & $132.5 \pm 20.2$ & $23.9 \pm 1.7$ & $32.1 \pm 1.8$ & $102.6 \pm 5.2$ & $7.44 \pm 0.02$ \\
\hline \multicolumn{7}{|c|}{ Picrotoxin $(n=3)$} \\
\hline Baseline & $81.7 \pm 7.6$ & $110.7 \pm 7.4$ & $19.9 \pm 2.1$ & $40.5 \pm 2.4$ & $97.5 \pm 0.6$ & $7.29 \pm 0.03$ \\
\hline Vehicle & $90.0 \pm 11.9$ & $116.8 \pm 10.7$ & $20.3 \pm 3.4$ & $32.5 \pm 1.4$ & $100.6 \pm 4.8$ & $7.44 \pm 0.01$ \\
\hline Drug & $103.7 \pm 11.6$ & $124.6 \pm 9.8$ & $21.8 \pm 3.0$ & $30.9 \pm 0.6$ & $102.3 \pm 2.6$ & $7.45 \pm 0.05$ \\
\hline \multicolumn{7}{|l|}{$\mathrm{ODQ}(n=7)$} \\
\hline Baseline & $82.7 \pm 8.8$ & $109.2 \pm 7.8$ & $21.0 \pm 1.4$ & $38.9 \pm 1.9$ & $101.1 \pm 3.2$ & $7.41 \pm 0.01$ \\
\hline Vehicle & $83.9 \pm 9.8$ & $110.6 \pm 9.1$ & $17.7 \pm 1.7$ & $38.0 \pm 1.8$ & $104.9 \pm 4.9$ & $7.42 \pm 0.01$ \\
\hline Drug & $76.1 \pm 9.6$ & $96.7 \pm 11.6$ & $17.4 \pm 1.4$ & $42.7 \pm 2.9$ & $102.2 \pm 3.4$ & $7.42 \pm 0.01$ \\
\hline \multicolumn{7}{|c|}{ Indomethacin $(n=4)$} \\
\hline Baseline & $102.4 \pm 9.5$ & $141.3 \pm 6.4$ & $25.1 \pm 2.0$ & $32.3 \pm 2.1$ & $109.5 \pm 8.2$ & $7.35 \pm 0.09$ \\
\hline Vehicle & $104.2 \pm 13.1$ & $144.6 \pm 7.9$ & $23.4 \pm 2.0$ & $31.6 \pm 1.4$ & $101.1 \pm 3.4$ & $7.44 \pm 0.01$ \\
\hline Drug & $111.2 \pm 15.3$ & $143.6 \pm 13.5$ & $24.8 \pm 3.4$ & $28.5 \pm 1.2$ & $105.3 \pm 3.7$ & $7.47 \pm 0.01$ \\
\hline \multicolumn{7}{|c|}{ NS-398 $(n=4)$} \\
\hline Baseline & $80.1 \pm 9.2$ & $107.3 \pm 1.3$ & $19.1 \pm 3.2$ & $36.5 \pm 2.3$ & $107.4 \pm 2.1$ & $7.42 \pm 0.02$ \\
\hline Vehicle & $75.8 \pm 0.8$ & $107.0 \pm 1.2$ & $17.8 \pm 2.0$ & $36.4 \pm 2.2$ & $104.6 \pm 4.0$ & $7.43 \pm 0.02$ \\
\hline Drug & $74.9 \pm 5.9$ & $105.4 \pm 4.9$ & $19.0 \pm 2.6$ & $35.9 \pm 4.2$ & $95.9 \pm 5.5$ & $7.42 \pm 0.02$ \\
\hline \multicolumn{7}{|c|}{ SC-560 $(n=4)$} \\
\hline Baseline & $71.3 \pm 7.9$ & $100.2 \pm 11.6$ & $23.5 \pm 3.4$ & $33.3 \pm 4.8$ & $97.1 \pm 0.5$ & $7.13 \pm 0.16$ \\
\hline Vehicle & $66.9 \pm 9.0$ & $90.7 \pm 12.4$ & $22.5 \pm 4.3$ & $40.2 \pm 4.6$ & $98.6 \pm 3.1$ & $7.25 \pm 0.11$ \\
\hline Drug & $63.6 \pm 9.9$ & $85.5 \pm 12.4$ & $23.6 \pm 4.7$ & $48.0 \pm 5.6$ & $92.6 \pm 8.4$ & $7.38 \pm 0.02$ \\
\hline \multicolumn{7}{|c|}{ MK-801 and picrotoxin $(n=5)$} \\
\hline Baseline & $92.8 \pm 11.7$ & $119.3 \pm 12.6$ & $22.4 \pm 1.9$ & $37.3 \pm 3.0$ & $97.2 \pm 2.7$ & $7.38 \pm 0.04$ \\
\hline Vehicle & $100.1 \pm 13.8$ & $123.2 \pm 13.5$ & $18.9 \pm 1.9$ & $35.2 \pm 0.8$ & $95.0 \pm 1.6$ & $7.40 \pm 0.02$ \\
\hline Drug & $97.3 \pm 8.7$ & $126.7 \pm 12.0$ & $20.8 \pm 3.1$ & $33.8 \pm 2.6$ & $95.7 \pm 2.4$ & $7.36 \pm 0.07$ \\
\hline \multicolumn{7}{|c|}{ Paxilline $(n=6)$} \\
\hline Baseline & $99.7 \pm 13.2$ & $135.9 \pm 11.2$ & $23.4 \pm 2.6$ & $32.5 \pm 0.1$ & $113.9 \pm 0.9$ & $7.42 \pm 0.01$ \\
\hline Vehicle & $98.4 \pm 11.0$ & $143.1 \pm 13.6$ & $21.2 \pm 3.0$ & $34.5 \pm 2.1$ & $105.8 \pm 2.3$ & $7.41 \pm 0.03$ \\
\hline Drug & $103.6 \pm 11.9$ & $141.1 \pm 12.3$ & $20.7 \pm 0.4$ & $32.1 \pm 6.1$ & $97.2 \pm 7.0$ & $7.47 \pm 0.03$ \\
\hline \multicolumn{7}{|l|}{$\mathrm{BaCl}_{2}(n=6)$} \\
\hline Baseline & $118.1 \pm 6.6$ & $142.8 \pm 11.4$ & $24.4 \pm 2.4$ & $36.4 \pm 2.3$ & $109.0 \pm 6.3$ & $7.48 \pm 0.01$ \\
\hline Vehicle & $111.8 \pm 7.2$ & $137.7 \pm 12.5$ & $20.6 \pm 2.2$ & $32.8 \pm 2.1$ & $95.9 \pm 3.2$ & $7.46 \pm 0.01$ \\
\hline Drug & $99.2 \pm 9.3$ & $122.0 \pm 14.5$ & $19.2 \pm 1.4$ & $31.0 \pm 2.5$ & $105.1 \pm 15.8$ & $7.46 \pm 0.01$ \\
\hline
\end{tabular}

Arterial pH and blood gas values were measured in all or a subset of rats ( $n$ ) at baseline and after vehicle or drug injection for each drug tested. All compounds tested had no effect on resting (BF ( $\mathrm{rCBF}$ ) over the entire experiment. a.u., Arbitrary units.

${ }^{a}$ All values are mean $\pm \mathrm{SEM} .{ }^{a}$ Before $\mathrm{LC}$ stimulation; ${ }^{b}$ after $\mathrm{LC}$ stimulation.

propynyloxy)-benzenehexanamide] $\left(10^{-3} \mathrm{M}\right)$, and paxilline $\left(10^{-5} \mathrm{M}\right)$. We present the most efficacious concentration and incubation time for each compound. Because complete blockade of NVC responses to sensory or electrical stimulation cannot be achieved even when combining high inhibitor or antagonist concentrations (Koehler et al., 2009; Leithner et al., 2010; Lecrux et al., 2011, 2012), except when indicated, only one compound and its corresponding vehicle were tested in each rat. CBF responses to LC stimulation were measured first under control conditions, then after vehicle injection, and finally, after drug administration. MAP, blood gases, and $\mathrm{pH}$ were comparable between all conditions (Table 1). To control for a possible effect of increased MAP on the evoked CBF, we used the $\alpha 1$-adrenoreceptor agonist phenylephrine ( $3 \mu \mathrm{g} / \mathrm{kg}$, 
i.v., femoral vein) (Sokrab and Johansson, 1989) to increase MAP to the same extent as observed during LC stimulation.

Data analyses. To evaluate the relative NA innervation density of neurons in the frontoparietal cortex, we determined the percentage of cells with NA terminals directly apposed to their soma and, as much as immunodetection allowed, proximal dendrites on 10-12 MIRAX-scanned semithin sections obtained from two different 60 - $\mu$ m-thick sections from each rat $(n=4)$. Such appositions correspond to nerve terminals or varicosities located within a maximum of $3 \mu \mathrm{m}$ from their targets (Vaucher et al., 2000), a distance essentially sufficient for physiological effects of the coeruleocortical NA system that uses a volume transmission mode not requiring morphological synaptic junctions (Séguéla et al., 1990; Fuxe et al., 2010). The total number of cells counted was as follows: PV $(n=3718), \operatorname{SOM}(n=4498), \operatorname{VIP}(n=1449), \operatorname{NOS}(n=1187)$, and ChAT $(n=612)$ interneurons and COX-2 $(n=6422)$ pyramidal cells. Their respective percentages of innervation in cortical layers II-VI were compared with a one-way ANOVA, followed by a Newman-Keuls post hoc test. For NOS interneurons, only large and darkly stained type I cells were quantified because small and lightly stained type II NOS neurons were not easily distinguishable in semithin sections. The cortical neurons recruited by LC stimulation were identified in $25-\mu \mathrm{m}$-thick sections double immunostained for c-Fos and the selected neuronal markers and quantified in the ipsilateral frontoparietal cortex in which the LDF probe was placed for CBF recordings. Double-labeled cells were counted in layers I-IV directly under the microscope and expressed as a percentage of the total population for each marker. The total numbers of cells counted were as follows: PV $(n=564), \operatorname{SOM}(n=588), \operatorname{VIP}(n=430), \operatorname{NOS}(n=$ $326)$, and COX-2 $(n=828)(n=6,2$ sections per rat). Comparison between different subtypes of double-labeled cells was achieved by a one-way ANOVA, followed by a Newman-Keuls post hoc test.

$\mathrm{CBF}$ values were measured in arbitrary units and analyzed with the Chart 7 software (ADInstruments). Changes in CBF induced by LC stimulation were taken at the peak response, expressed as percentage changes from baseline, and compared between ipsilateral and contralateral sides by paired Student's $t$ tests. LC-induced ipsilateral CBF responses between saline- and DSP-4-treated rats were compared by unpaired Student's $t$ tests. A one-way ANOVA, followed by a Newman-Keuls post hoc test was used to compare the effect of LC stimulation on CBF responses and physiological parameters in control, vehicle, and drug conditions. For graphic representation, CBF was averaged every $1 \mathrm{~s}$ starting 1 min before the stimulation and until $1 \mathrm{~min}$ after and expressed as percentage change compared with the $1 \mathrm{~min}$ average prestimulus baseline. All values are means \pm SEM, and statistical analyses were performed with the GraphPad Prism4 software. $p<0.05$ was considered significant.

\section{Results}

\section{LC-NA afferents target different cortical neurons}

Cortical DBH-immunopositive fibers were distributed across all layers of the frontoparietal cortex (Fig. 1B), as expected for cortical NA innervation (Séguéla et al., 1990). In doubleimmunostained semithin sections, the brown-immunopositive $\mathrm{DBH}$ fibers were easily distinguishable from the blue-gray immunostained cortical neurons (Fig. $1 A, C$ ). Quantitative analysis across all cortical layers, except for COX-2 pyramidal cells that distribute predominantly in layers II/III (Kaufmann et al., 1996), demonstrated that similar proportions $(20-24 \%)$ of the total populations of COX-2 pyramidal cells and PV, SOM, VIP, NOS, and ChAT interneurons were targeted by NA varicose fibers on their cell soma or proximal dendrites, as illustrated for COX-2 and SOM cells (Fig. 1 A,C). A detailed analysis showed that these cells distributed quite evenly among the different cortical layers (Fig. 1D). Only VIP- and ChAT-immunoreactive dendrites were slightly less innervated within deeper layer VI (Fig. 1D). Although it is reasonable to assume that somatic innervation has greater efficiency than that on distal dendrites and dendritic spines that were not investigated in the present study (Segev, 2006), the rather uniform innervation pattern among cortical neurons pointed to the important role of receptor subtype and distribution in the final output response (Fuxe et al., 2010). Hence, we then identified the neuronal circuitry recruited after NA release from activated LC-NA afferents using c-Fos immunohistochemistry as a marker of neuronal activation.

\section{Subsets of pyramidal cells and GABA interneurons recruited by LC stimulation}

Stimulation of the LC resulted in a selective increase in c-Fos immunoreactivity in the ipsilateral cortex (Fig. $2 A$ ), with virtually no c-Fos-positive neurons in the contralateral side (Fig. 2B). No c-Fos immunostaining was detected in the cortex of control rats that received no current delivery (data not shown). Together, these findings indicate that the ipsilateral neuronal activation visualized by c-Fos immunohistochemistry was LC stimulation related. Moreover, the cortical c-Fos increase was prevented by cortical NA denervation with DSP-4 (Fig. 2C), further demonstrating that cortical release of NA from LC terminals is required for c-Fos induction in cortical neurons. In further investigating the identity of cells recruited by LC stimulation in doubleimmunostained sections, we found that c-Fos-positive nuclei were mainly located within GABA interneurons that colocalize PV $(35.9 \pm 0.4 \%)$, SOM $(36.0 \pm 3.7 \%)$, and NOS $(33.5 \pm 5.2 \%)$, whereas significantly less VIP interneurons $(16.3 \pm 1.7 \%, p<$ $0.01)$ and COX -2 pyramidal cells $(21.5 \pm 3.6 \%, p<0.05)$ were recruited after LC stimulation (Fig. $2 D-I$ ). Numerous COX-2 immunonegative pyramidal cells were also c-Fos positive after LC stimulation, but they were not quantified because of their high number. This broad network of excitatory and inhibitory neurons, which also closely associate with the cortical microvasculature and perivascular astrocytes (Cauli et al., 2004; Wang et al., 2005; Hamel, 2006), likely drives the changes in perfusion that accompany the increase in cortical activity induced by stimulation of LC-NA afferents. Thus, we measured the alterations in cortical CBF in rats submitted to the exact same stimulation paradigms.

\section{Bilateral increases in CBF after LC stimulation}

Baseline CBF recorded in the frontoparietal cortex was very stable and promptly increased bilaterally after electrical stimulation of the LC, and it slowly returned to baseline after stimulus (Fig. 3A). Ipsilateral $\mathrm{CBF}$ increases were significantly larger than those measured on the contralateral side $(52.2 \pm 4.8$ vs $31.1 \pm 2.4 \%$, $p<$ 0.01 ) (Fig. 3B). Interestingly, MAP also increased during LC stimulation ( $33 \pm 6.5 \%, p<0.01, n=10$ ) (Fig. $3 B$ ), consistent with a role for LC in cardiovascular regulation (Chida et al., 1983; Drolet and Gauthier, 1985; Berecek and Mitchum, 1986). All rats that displayed CBF and MAP increases after LC stimulation had electrodes correctly implanted in the LC, as verified on $\mathrm{DBH}$ immunostained coronal sections (Fig. 3C). No changes in blood gases $\left(\mathrm{pCO}_{2}\right.$ and $\left.\mathrm{pO}_{2}\right)$ or $\mathrm{pH}$ were observed during the stimulusevoked increases in CBF (Table 1).

Because variations in systemic MAP might affect cortical CBF in conditions in which autoregulation is altered (Häggendal and Johansson, 1965; Harper, 1966), we addressed this possibility by pharmacologically increasing MAP with the $\alpha 1$-adrenergic receptor agonist phenylephrine to the same extent as that observed during LC stimulation (31.1 $\pm 3.4 \%$ ) (Fig 4A). Phenylephrine induced small and symmetrical, albeit not significant, increases in $\mathrm{CBF}$ on both sides of the frontoparietal cortex (14.8 \pm 1.5 and $18.9 \pm 3.2 \%)$ that were significantly lower than CBF increases 

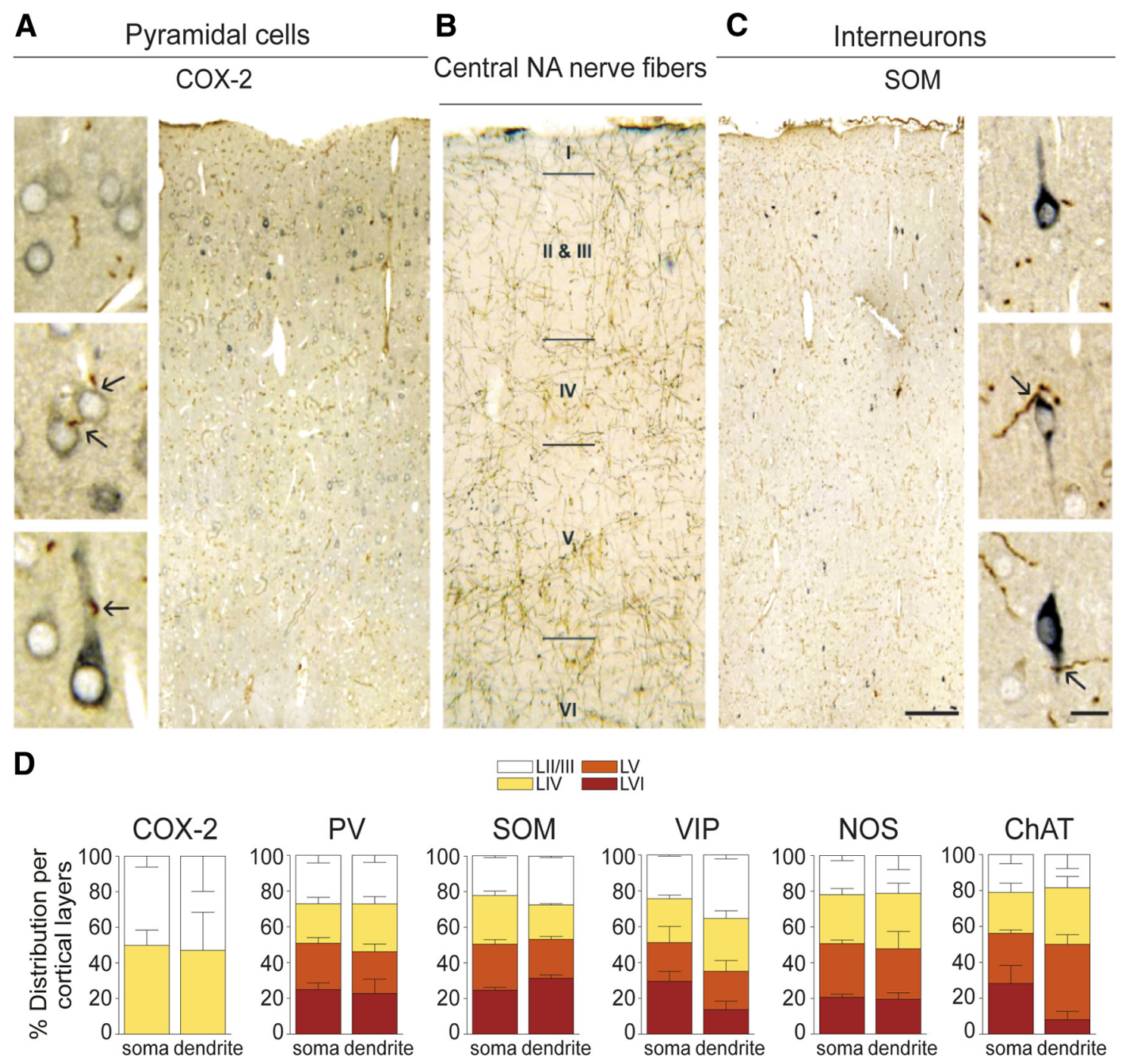

Figure 1. NA innervation of cortical COX-2 pyramidal cells and distinct subsets of GABA interneurons. $A, C$, Photomicrographs of semithin, double-immunostained sections for NA fibers and COX-2 pyramidal cells or SOM interneurons. The brown DAB-immunodetected NA fibers contact the blue- gray SG-stained neurons on their cell soma or proximal dendrites (black arrows on high-magnification pictures). $\boldsymbol{B}$, Photomicrographs of DBH-immunostained NA innervation in the frontoparietal cortex detected with DAB. D, Quantitative analysis of NA fibers contacting cortical COX-2 pyramidal cells and PV-, SOM-, VIP-, NOS-, or ChAT-expressing GABA interneurons. Cells were counted across all cortical layers except for COX-2 pyramidal cells that distribute mainly in layers II/III and IV. The percentage of cells innervated on their cell soma or proximal dendrites was comparable across all cortical layers. Values are mean \pm SEM. Scale bars: $100 \mu \mathrm{m}$; high magnification, $10 \mu \mathrm{m}$.

observed after LC stimulation (Fig. 4A). These findings convincingly indicated that the bilateral and asymmetric increases in MAP induced by LC stimulation was pathway specific and within the limit of autoregulation.

To further confirm that both the CBF and MAP increases were mediated centrally by activation of the LC-NA pathway, we depleted cortical NA axon terminals with DSP-4, a potent neurotoxin that destroys exclusively NA projections from the LC but not those from non-LC neurons (Fritschy and Grzanna, 1989). This treatment resulted in a massive reduction in cortical NA nerve fiber density compared with saline-injected rats, with sparing of peripheral NA innervation, as evidenced by the intact DBH-immunostained fibers on the cerebral arteries of DSP-4treated rats (Fig. 4B). Consistent with the loss of cortical NA innervation and previous studies showing reductions in cortical NA levels (Jonsson et al., 1981), a dramatic reduction in the cortical CBF response to LC stimulation $(-70.9 \pm 6.5 \%, p<0.001)$ and in MAP $(-95.9 \pm 6.5 \%, p<0.001)$ was evidenced in DSP4-treated rats (Fig. 4C).
Knowing that cortical NA released from LC-NA terminals acts on both $\alpha$ - and $\beta$-adrenergic receptors on cortical cells (Nicholas et al., 1996) to modulate cortical activity (Berridge and España, 2000), we evaluated the contribution of these receptors in the evoked CBF response. Blockade of $\alpha$-receptors with phentolamine and of $\beta$-receptors with propranolol significantly decreased the evoked CBF response to LC stimulation $(-38.7 \pm 5.7 \%, p<0.01$ and $-30.6 \pm 4.9 \%$, $p<0.05$, respectively) (Fig. $4 D$ ). These results confirm a role for adrenoceptors in the CBF response to LC stimulation, as reported for changes in cortical activity under phasic LC-NA system activation (Waterhouse et al., 1998). The combination of stimulation and lesioning approaches together with the use of noradrenergic receptor antagonists demonstrate that changes in cortical CBF are centrally mediated and require intact NA neurons from the LC. Moreover, because parenchymal NA mediates negligible effects on contractile smooth muscle $\alpha$-adrenoceptors in brain microarterioles (Kissen and 

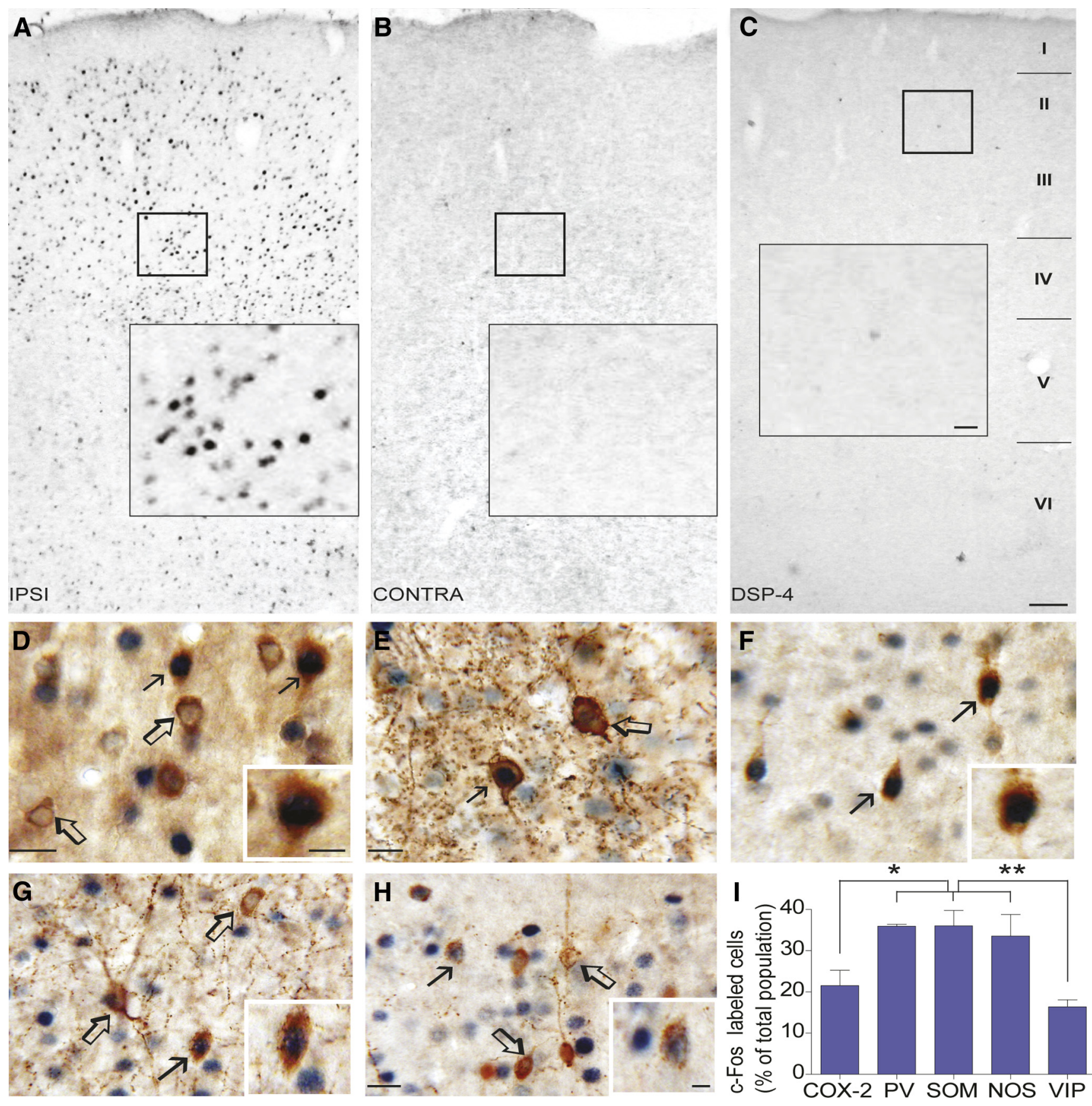

Figure 2. Identification of the recruited cortical neuronal network by LC stimulation. $A-C$, Photomicrographs of immunostained sections for $C$-Fos in the frontoparietal cortex induced by $L C$ stimulation in controls or DSP-4 treated rats. D-H, Photomicrographs of double-immunostained sections for c-Fos (SG, blue-gray nuclei) and different neuronal markers (DAB, brown): COX-2 pyramidal cells $(\boldsymbol{D})$ and GABA interneurons expressing PV $(\boldsymbol{E})$, SOM $(\boldsymbol{F})$, NOS $(\boldsymbol{G})$, or VIP $(\boldsymbol{H})$. Filled arrows show activated cells, whereas open arrows indicate absence of $\mathrm{c}-$ Fos expression. $\boldsymbol{I}$, Quantitative analysis of double-labeled c-Fos COX-2 pyramidal cells or GABA interneuron subtypes in layers II-IV of the ipsilateral frontoparietal cortex. ${ }^{*} p<0.05$, ${ }^{* *} p<0.01$, one-way ANOVA and a Newman-Keuls post hoc test. Scale bars: $\mathbf{A}-\mathbf{C}, 100 \mu \mathrm{m}$; insets, $20 \mu \mathrm{m} ; \boldsymbol{D}-\mathbf{G}, 20 \mu \mathrm{m}$; insets, $10 \mu \mathrm{m}$.

Weiss, 1991), our results suggest that the hyperemic response primarily results from changes in neuronal activity.

\section{Mediators of the hemodynamic responses to LC stimulation}

Glutamatergic neurotransmission and COX-2 pyramidal cells Previous electrophysiological studies have emphasized the role of NA in the modulation of cortical glutamatergic neurotransmission (Nowicky et al., 1992, Dinh et al., 2009), the latter being the main determinant for the coupling between increased cortical activity and hemodynamic alterations (Attwell and Iadecola, 2002). This is consistent with the numerous c-Fos-positive pyramidal-shaped cells found in our study (not quantified) and, to a lesser extent, COX-2-immunopositive pyramids $(\sim 20 \%)$. Accordingly, NMDA receptor antagonism (MK-801) markedly decreased the CBF response evoked by LC stimulation $(-56.2 \pm$ $7.3 \%, p<0.001$ ) (Fig. $5 A, C)$ as did, albeit to a smaller extent, blockade of AMPA/kainate receptors with CNQX $(-23.4 \pm$ $6.9 \%$, at $10 \mathrm{~min}, p<0.05$ ) (Fig. $5 C$ ). Involvement of group I mGluRs was also evaluated with the combined blockade of mGluR1 and mGluR5 with MPEP and LY367385 [(S)- $(+)-\alpha-$ amino-4-carboxy-2-methylbenzeneacetic acid], which signifi- 
A

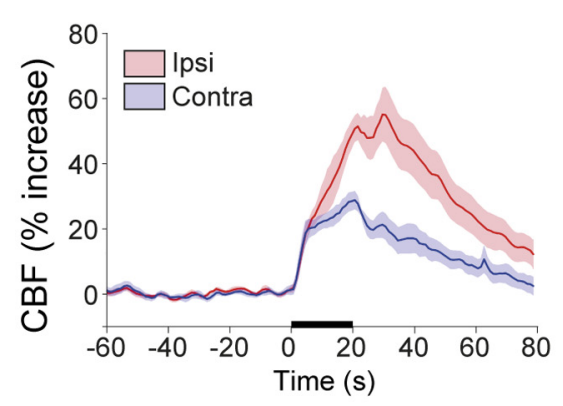

B

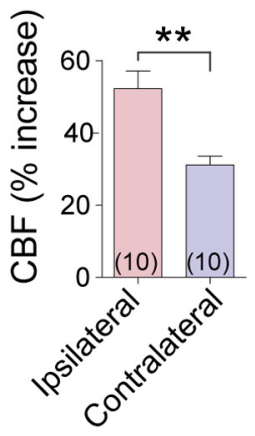

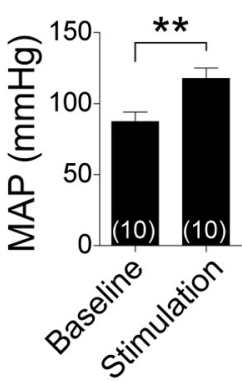

C

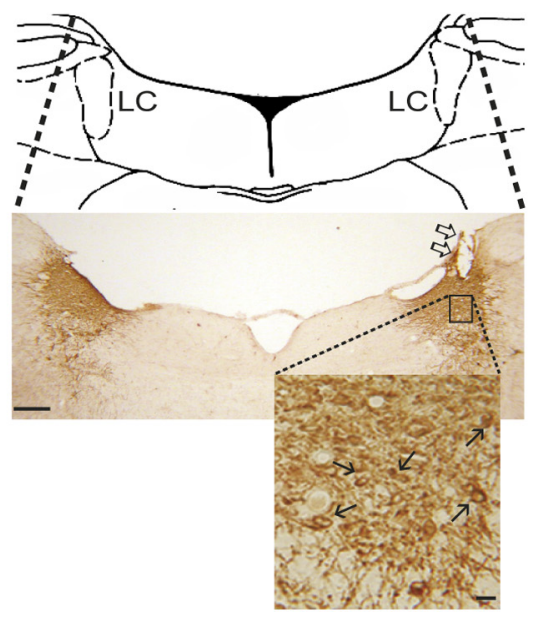

Figure 3. Increased CBF and MAP after LC stimulation. $A$, Average CBF responses to LC stimulation (black line on the $x$-axis) from baseline observed in the ipsilateral (pink) and contralateral (blue) cortices. Shaded areas denote SEM. B, Ipsilateral cortical CBF increases induced by LC stimulation are significantly larger than those measured on the contralateral side. Blood pressure is also significantly increased during LC stimulation. C, Representative section showing the location of the stimulating electrode (open arrows) in the LC immunostained for DBH (black arrows point to packed DBH-immunopositive neurons). Values are mean \pm SEM. ${ }^{* *} p<0.01, t$ test. Scale bars: $250 \mu \mathrm{m}$; high magnification, $25 \mu \mathrm{m}$.

cantly decreased the evoked CBF response $(-31.5 \pm 7.3 \%, p<$ 0.05) (Fig. 5C). Knowing that COX-2 pyramidal cells synthesize and release COX-2-derived vasoactive prostanoids identified as important contributors in the NVC response to sensory input (Koehler et al., 2009), we investigated their contribution in hemodynamic response to LC stimulation. Unexpectedly, both nonselective COX inhibition with indomethacin and selective COX-2 inhibition with NS-398 [N-[2-(cyclohexyloxy)-4-nitrophenyl] methanesulfonamide], although having no effect on resting CBF (Table 1), strongly potentiated the CBF response evoked by LC stimulation $(+43.6 \pm 11.1 \%, p<0.05$ or $+48.1 \pm 13.1 \%, p<0.01$ ) (Fig. $5 B, C)$. In contrast, no significant $\mathrm{CBF}$ changes were observed with the selective COX-1 inhibitor SC-560 [5-(4-chlorophenyl)-1(4-methoxyphenyl)-3-trifluoromethyl pyrazole] $(2.7 \pm 2.2 \%)$ (Fig. $5 C$ ), as found after sensory or basal forebrain stimulation (Niwa et al., 2000; Lecrux et al., 2011, 2012).

\section{GABAergic neurotransmission and a role for $N O$}

Based on our neuroanatomical findings that GABA interneurons are targeted by LC-NA afferents (Fig. 1D) and recruited by LC stimulation (Fig. 2E-I) and on their documented role, via $\mathrm{GABA}_{\mathrm{A}}$ receptor activation, in NVC responses to basal forebrain and sensory stimulation (Kocharyan et al., 2008; Lecrux et al., 2011), we tested their contribution in the CBF response to LC stimulation. We found that $\mathrm{GABA}_{\mathrm{A}}$ receptor blockade with picrotoxin significantly decreased the evoked hemodynamic response $(-47.2 \pm 6.4 \%, p<0.05)$ (Fig. $5 C$ ). Interestingly, combined blockade of NMDA and $\mathrm{GABA}_{\mathrm{A}}$ receptors with a mixture of MK-801 and picrotoxin did not alter the LC-evoked CBF response $(4.0 \pm 16.5 \%)$, despite their potent individual effects. This finding likely resulted from the mixed effect of NA on cortical activity (Sato and Kayama, 1983; Devilbiss and Waterhouse, $2000,2004)$. Indeed, the NA modulation of GABA signaling onto cortical pyramidal cells can be inhibitory or excitatory depending on interneuron subtype (Kawaguchi and Shindou, 1998) and cortical layer (Salgado et al., 2011). In agreement with a significant proportion $(>30 \%)$ of $\mathrm{NO}$-producing GABA interneurons being recruited by LC stimulation (c-Fos positive) (Fig. 4G,I), we found that blocking the NO-sensitive guanylyl cyclase with the potent and selective inhibitor ODQ resulted in a signifi- cantly reduced LC-evoked CBF response $(-35.3 \pm 9.2 \%, p<0.05)$ (Fig. 5C).

Astroglio-vascular interactions in the $L C$-evoked CBF response In line with the anatomical relationships between LC-NA afferents and astroglial cells and, particularly, perivascular astrocytes (Paspalas and Papadopoulos, 1996, Cohen et al., 1997), we found that impairing astroglial oxidative metabolism with fluorocitrate, an inhibitor of the astroglial enzyme aconitase (Zielke et al., 2007), significantly decreased the LC-evoked CBF response $(-35.4 \pm 5.9 \%, p<0.01)$ (Fig. 5C). Astrocytic $\mathrm{Ca}^{2+}$ transients, which are rapidly induced by LC stimulation (Bekar et al., 2008), have been linked to increased CBF through the synthesis and release of arachidonic acid-derived vasodilatory messengers, particularly the EETs (Koehler et al., 2009). Accordingly, blockade of EET synthesis with the cytochrome P450 epoxygenase inhibitor MS-PPOH potently attenuated the LC-evoked $\mathrm{CBF}$ response $(-57.2 \pm 5.9 \%, p<0.001)$ (Fig. $5 C, 6)$. The putative EET receptor antagonist 14,15-epoxyeicosa-5(Z)-enoic acid $(14,15$-EEZE) also significantly impaired, albeit to a smaller extent, the LC-induced CBF response $(-31.2 \pm 6.2 \%, p<0.05)$ (Fig. $5 C$ ). This proportionally smaller decrease as well as that after blockade of astroglial metabolism may emphasize that EETs are readily available from membrane stores (Harder et al., 1998) and can induce dilation through more than one receptor (Koehler et al., 2009). Astrocytic $\mathrm{Ca}^{2+}$ elevation has also been linked to $\mathrm{K}^{+}$ release from astrocytic endfeet via BK channels that then activate Kir channels on arteriolar smooth muscle cells to induce relaxation (Filosa et al., 2006; Girouard et al., 2010). Therefore, we tested the implication of BK and Kir $\mathrm{K}^{+}$channels in the LCinduced hyperemic response and found that their respective blockade with paxilline $(-52.4 \pm 8.8 \%, p<0.05)$ and $\mathrm{BaCl}_{2}$ $(-40.5 \pm 2.8, p<0.05)$ exerted potent reducing effects on the evoked CBF response (Fig. $5 C, 6$ ).

\section{Discussion}

Our data demonstrate that the role of LC in the regulation of cortical CBF should be considered as a classic model of functional hyperemia, with a selectively recruited cortical neuronal network driving increases in cortical perfusion. Our results further support the high sensitivity of hemodynamic signals to detect subtle 
A

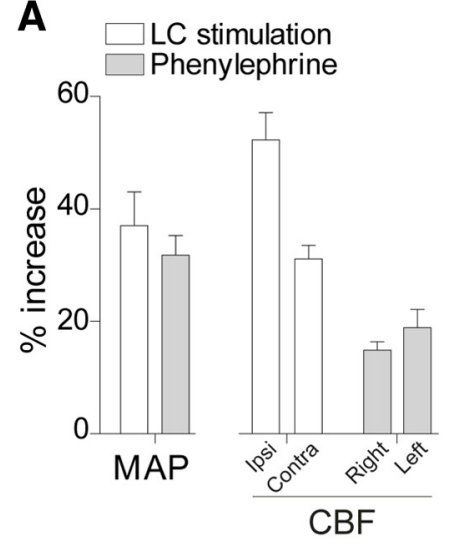

B

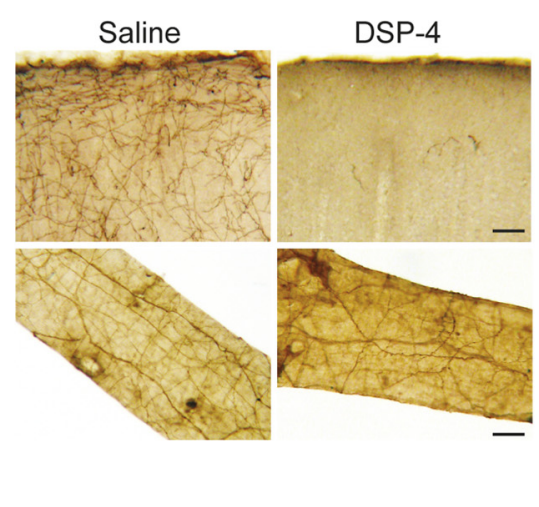

C
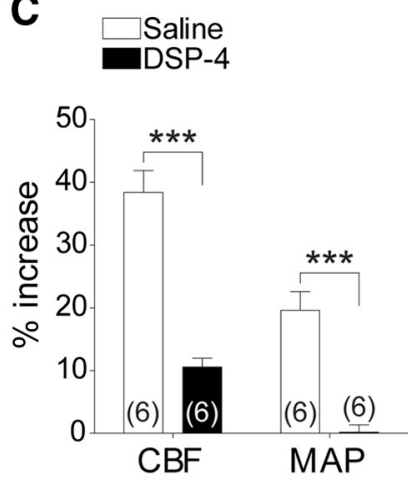
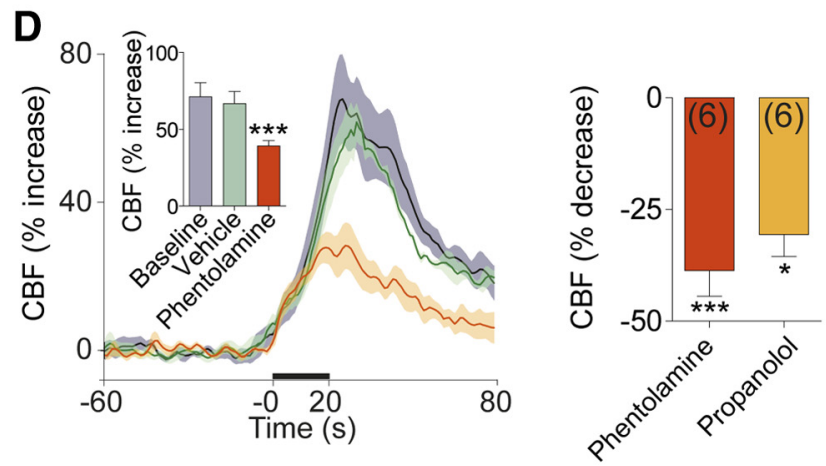

Figure 4. The LC-NA system in the CBF response. A, Pharmacological increase of MAP with the $\alpha 1$-adrenoceptor agonist phenylephrine had no significant effect on CBF. $\boldsymbol{B}$, Rats treated with DSP-4 showed significant reduction of NA innervation (DBH immunostaining) in the frontoparietal cortex compared with saline-injected animals. In contrast, the NA innervation of the cerebral arteries was unaltered in DSP-4-treated rats (bottom row). C, DSP-4 lesioning reduced both the CBF and MAP increases induced by LC stimulation. D, Average CBF responses to LC stimulation (black line on $x$-axis) at baseline, following vehicle or $\alpha$-adrenoceptor antagonism with phentolamine (left). The LC-induced CBF increases were significantly decreased following blockade of $\alpha$-adrenoceptors (phentolamine) and $\beta$-adrenoceptors (propranolol) (right). The number of rats used is indicated within parentheses. None of the vehicles affected baseline or evoked (BF responses. Values are mean \pm SEM (shaded areas) and are expressed as percentage change from the evoked CBF response after vehicle injection. ${ }^{*} p<0.05$, ${ }^{* * *} p<0.001$, one-way ANOVA and Newman-Keuls post hoc test. Scale bars (in $\boldsymbol{B}$ ): top row, $100 \mu \mathrm{m}$; bottom row, $50 \mu \mathrm{m}$.

changes in neuronal activity, in which electrophysiological (Sirotin and Das, 2009; Figley and Stroman, 2011; Devonshire et al., 2012) or anatomical (c-Fos upregulation; this study) measures fail.

\section{Cortical neuronal targets of the LC-NA pathway}

NA-containing axon terminals are known to contact pyramidal cells in rat visual and frontoparietal cortex (Papadopoulos et al., 1989), and NA appositions were found on distal dendrites or dendritic spines of pyramidal cells in the frontal, parietal, and occipital cortex (Séguéla et al., 1990). Our observations expand these findings by showing that $\mathrm{DBH}$-immunoreactive varicose fibers contacted the cell soma and proximal dendrites of COX-2expressing pyramidal cells in the frontoparietal cortex. The relationship between NA fibers and cortical GABA interneurons has been studied only in rat visual cortex, in which NA terminals targeted similar proportions $(20-27 \%)$ of SOM, neuropeptide $\mathrm{Y}$ (NPY), or VIP interneurons (Paspalas and Papadopoulos, 1999). Our study reached similar conclusions and further showed that the fast-spiking PV cells, which are distinct from the SOM/NPY/ NOS and VIP populations of GABA interneurons (Kubota et al., 1994) and important regulators of cortical activity, are contacted by LC-NA afferents throughout the frontoparietal cortex. This was also true for type 1 NOS interneurons, a subset of the SOM family (Kubota et al., 1994; Cauli et al., 2004), and we further identified interactions between DBH-immunoreactive fibers and ChAT interneurons, as reported in rat globus pallidus (Rodrigo et al., 1998). These findings reiterate the broad targets of cortical LC-NA afferents and the importance of the NA receptor localization when volume transmission is involved (Fuxe et al., 2010).

\section{Cortical circuitry recruited by activation of the LC-NA pathway}

LC stimulation elicited a widespread c-Fos upregulation throughout the ipsilateral cortex, consistent with the predominant ipsilateral projections of the LC (Jones and Moore, 1977), a response abolished by cortical NA denervation with DSP-4. Previous work found similar c-Fos upregulation after enhancement of NA release (Stone et al., 1993) or mechanical LC stimulation (Stone et al., 1995). Compared with VIP interneurons, a larger proportion of PV and SOM/NOS interneurons, which also express calbindin (Kubota et al., 1994, Gonchar and Burkhalter, 1997), were c-Fos positive. This activation pattern matches very well the reported ability of NA to selectively regulate GABA interneuron activity, inducing depolarization of PV and SOM interneurons and hyperpolarization of VIP cells (Kawaguchi and Shindou, 1998), and differs from those induced by activation of basal forebrain (Kocharyan et al., 2008; Lecrux et al., 2012) or thalamic (Lecrux et al., 2011) cortical afferents. Our c-Fos data also support the reported modulation of pyramidal cell excitability through activation of NA receptors (Ji et al., 2008; Kobayashi et al., 2008; Dinh et al., 2009), as shown here for COX-2 pyramidal cells that were recruited by LC stimulation. Interestingly, as in DSP-4-treated rats, c-Fos upregulation was significantly attenuated by lesion of the LC with 6-hydroxydopamine (Stone 
et al., 1993; 1995). Hence, the virtual absence of c-Fos-immunopositive cells in the contralateral cortex to LC stimulation may result from a failure to meet the required threshold for membrane depolarization and increases in firing rate that are needed for the c-Fos-dependent $\mathrm{Ca}^{2+}$ entry (Fields et al., 1997). Indeed, the sparse release of NA from contralateral LC terminals may not allow for a sufficiently strong and persistent activation of adrenoceptors mediating neuronal depolarization (Cirelli and Tononi, 2000), as was the case when virtually all NA terminals had disappeared after DSP-4 lesion. Despite this "apparent silence" in neuronal activity on the contralateral cortex after LC stimulation, there was a small but significant increase in CBF. These findings point to the high sensitivity of hemodynamic signals that can be altered by subthreshold neuronal activity (Figley and Stroman, 2011; Devonshire et al., 2012) or even in the absence of clear neurophysiological changes (Sirotin and Das, 2009). Alternatively, they may support that hemodynamic responses are more closely related to astrocytic changes than neuronal activity per se (Figley and Stroman, 2011). Additional investigations involving optogenetic stimulation of LC-NA neurons or cortical terminals would help unequivocally identify the recipient cortical neuronal network and hemodynamic outcome.

\section{Stimulation of LC-NA afferents increases cortical perfusion}

LC stimulation increases NA release in the cortex (Florin-Lechner et al., 1996) and promotes both cortical neuronal (Berridge and Foote, 1991) and astrocytic (Bekar et al., 2008) activity, the former in line with our findings of upregulated c-Fos in a broad network of cortical neurons. LC stimulation would thus be expected to increase CBF, as evidenced in our study. Surprisingly, however, no change (Mraovitch et al., 1985) or decreased CBF have been reported previously in monkey (Raichle et al., 1975), cat (Goadsby and Duckworth, 1989), and rat (de la Torre, 1976) after LC stimulation. Explanations for this discrepancy may include differences in species, stimulation paradigms, and methods of CBF measurement. In cat, the distribution of NA neurons in LC is more diffuse than in rat (Jones and Moore, 1974), and LC stimulation may recruit other neuronal systems. Most importantly, previous parameters of LC electrical stimulation were either ill-defined (Mraovitch et al., 1985) or corresponded to high-intensity currents (500 $\mu \mathrm{A})$ (de la Torre, 1976) later shown to exert suppressive effects on cortical activity (Kayama et al., 1982; Sato et al., 1989), hence compatible with the observed decrease in CBF. In contrast, the low stimulus current used here has been shown to activate cells within a maximal radius of $150 \mu \mathrm{m}$ (Devilbiss and Waterhouse, 2011), thus minimizing current spread beyond the borders of the LC nucleus. Chemical LC stimulation in monkeys was also reported to decrease cortical CBF (Raichle et al., 1975), but no post hoc test.
B

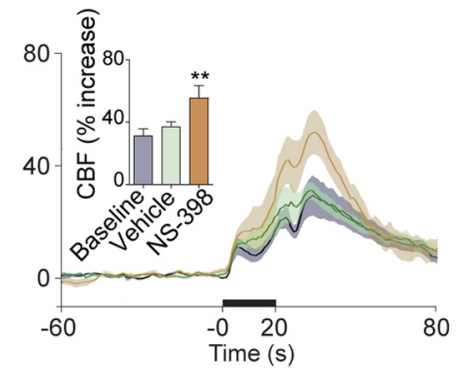

Neurotransmitters Vasodilatory mediators Astrocytic signalling

(4)
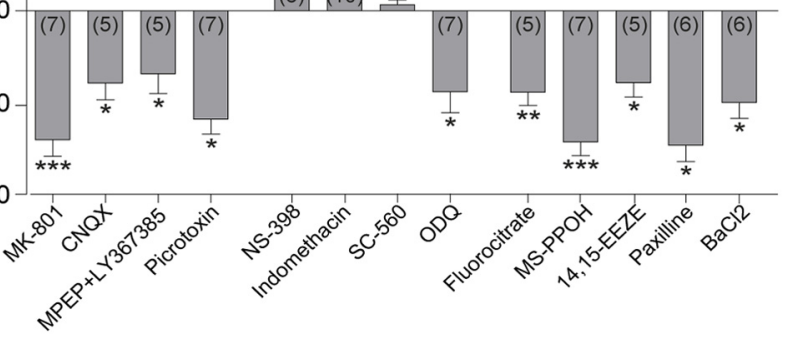

Figure 5. Pathways involved in the $L C-N A$-evoked CBF responses. $A-C$, Average CBF responses to $L C$ stimulation (black line on $x$-axis) at baseline, after vehicle or NMDA receptor antagonism (MK-801) $(\boldsymbol{A}, n=7)$ or COX-2 inhibition (NS-398) $(\boldsymbol{B}, n=6)$. Shaded areas denote SEM. $C$, Summary of blockade of specific neurotransmitter receptors, synthesis of dilatory mediators, or EE synthesis with MS-PPOH and the putative EET receptor antagonist 14,15-EEZE. Blockade of $\mathrm{K}^{+}$fluxes with paxilline or $\mathrm{BaCl}_{2}$

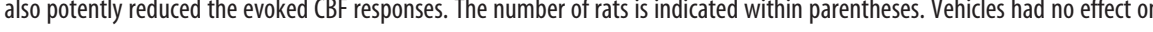

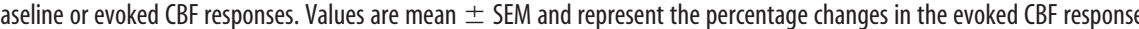
compared with vehicle injection. ${ }^{*} p<0.05,{ }^{* *} p<0.01,{ }^{* * *} p<0.001$ versus vehicle by one-way ANOVA and a Newman-Keuls

information on the specificity of LC activation or its impact on cortical NA release was provided. Interestingly, subsequent studies in monkey or rat using intracerebroventricular (MacKenzie et al., 1976b) or blood-brain barrier opening and intravenous (Edvinsson et al., 1978) NA administration found increases in cortical perfusion, oxygen consumption, and glucose uptake. Moreover, pharmacologic enhancement of brain endogenous NA release resulted in CBF and metabolism increases that were reduced by $\beta$-adrenoceptor antagonists (MacKenzie et al., 1976a).

\section{Mediators of the hemodynamic response to LC stimulation}

Consistent with the recruitment of pyramidal cells, predominantly NMDA but also AMPA and mGluR receptors contributed to the $\mathrm{LC}$-evoked $\mathrm{CBF}$ response. Unexpected was our finding that COX-2 inhibition potentiated the LC-evoked CBF response, whereas studies on the sensory system consistently found reduced responses after COX-2 inhibition (Niwa et al., 2000; Stefanovic et al., 2006; Lecrux et al., 2011). Interestingly, the COX-derivative thromboxane A2 has been found to inhibit NA release in hippocampal slices (Nishihara et al., 2000), suggesting that, if a similar mechanism occurs in the cerebral cortex, COX inhibition would promote the enhancing effect of NA on cortical 
A

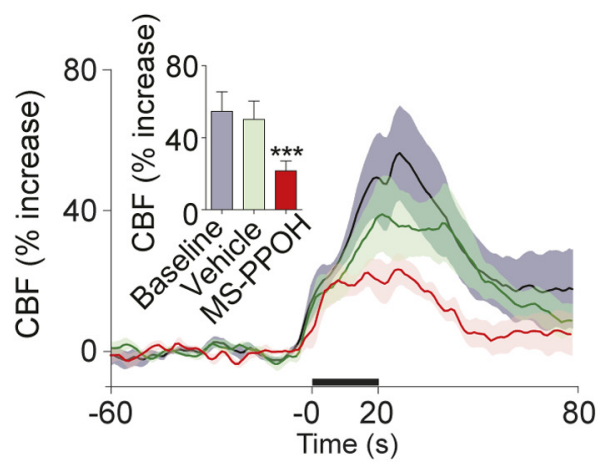

B

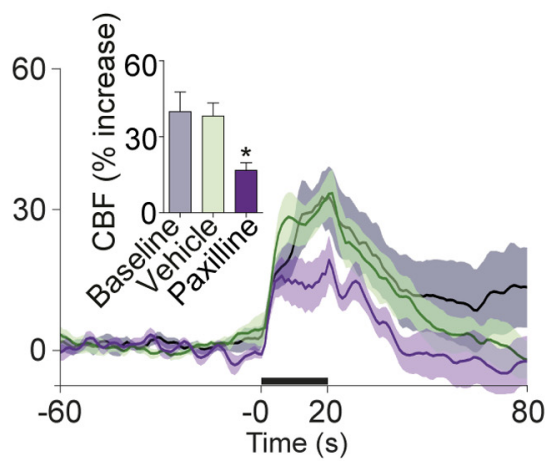

C

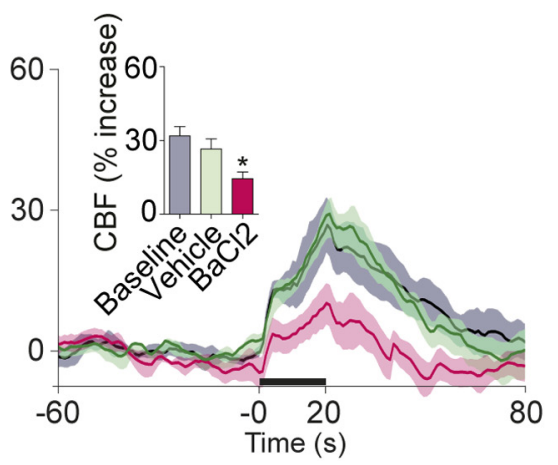

Figure 6. Role of EET signaling and $\mathrm{K}^{+}$fluxes in the evoked (BF response by LC stimulation. $A-C$, Average CBF responses to $\mathrm{LC}$ stimulation (black line on $x$-axis) at baseline, after vehicle or inhibition of EET synthesis with MS-PPOH $(\boldsymbol{A}, n=7)$, blockade of BK channels with paxilline $(\boldsymbol{B}, n=6)$, or Kir channels with $\mathrm{BaCl}_{2}(\boldsymbol{C}, n=6)$. Shaded areas denote SEM. Vehicles had no effect on baseline or evoked CBF responses. Values are mean \pm SEM. ${ }^{*} p<0.05,{ }^{* * *} p<0.001$ versus vehicle by one-way ANOVA and a Newman-Keuls post hoc test.

activity and perfusion. Additionally, COX-derived arachidonic acid products mediate the NA-induced vasoconstriction in cerebral arteries (Usui et al., 1987), raising the possibility that blocking their synthesis could revoke their opposing effect on the dominant neurally driven dilatory response. Our findings that $\mathrm{GABA}$, through $\mathrm{GABA}_{\mathrm{A}}$ receptor activation, contributed to the LC-evoked CBF responses agree with NA increasing cortical activity through regulation of specific GABA interneurons strategically located across cortical layers (Kawaguchi and Shindou, 1998; Salgado et al., 2012). We also found that NO, likely released from activated NOS-containing GABA interneurons, was involved in the LC-evoked CBF response consistent with its role in the NVC response to sensory stimulation (Lindauer et al., 1999; Liu et al., 2008).

The most pronounced reductions $(\sim 60 \%)$ in the evoked CBF response were obtained when blocking EET synthesis or BK channels. Our current understanding of the functional neurogliovascular unit suggests that increased $\mathrm{Ca}^{2+}$ signaling in astrocytic endfeet promotes EET synthesis and activates BK channels. The latter induce the release of $\mathrm{K}^{+}$in the perivascular space, which then activates Kir channels on microarterioles, resulting in hyperpolarization and dilatation (Dunn and Nelson, 2010; Higashimori et al., 2010; Farr and David, 2011). Although EET synthesis and $\mathrm{BK}$ channels may not be exclusively astroglial, the close association between cortical LC-NA terminals and perivascular astrocytic endfeet (Cohen et al., 1997), the presence of various subtypes of adrenoceptors on brain astrocytes (Hertz et al., 2010), and the rapid $\alpha$-adrenoceptor-mediated increase in $\mathrm{Ca}^{2+}$ transients in cortical astroglial endfeet after LC stimulation (Bekar et al., 2008) all support a role for astrocytes as intermediaries in transmuting NA neuronal signals into vascular responses.

\section{Concluding remarks}

Our data demonstrate that activation of the LC-NA pathway, particularly important in conditions of arousal and increased alertness, enhances both cortical activity (c-Fos) and CBF. The cortical cellular network recruited by stimulation of the LC-NA system promoted cortical glutamate release from pyramidal cells, likely through direct activation and after interneuron disinhibition. The data further stress the important role of $\mathrm{K}^{+}$fluxes and EET signaling, presumably at the gliovascular interface, in this hemodynamic response.

\section{References}

Aston-Jones G, Bloom FE (1981) Norepinephrine-containing locus coeruleus neurons in behaving rats exhibit pronounced responses to nonnoxious environmental stimuli. J Neurosci 1:887-900. Medline

Aston-Jones G, Segal M, Bloom FE (1980) Brain aminergic axons exhibit marked variability in conduction velocity. Brain Res 195:215-222. CrossRef Medline

Attwell D, Iadecola C (2002) The neural basis of functional brain imaging signals. Trends Neurosci 25:621-625. CrossRef Medline

Bekar LK, He W, Nedergaard M (2008) Locus coeruleus alpha-adrenergicmediated activation of cortical astrocytes in vivo. Cereb Cortex 18:27892795. CrossRef Medline

Berecek KH, Mitchum TN (1986) Role of vasopressin in the cardiovascular response to stimulation of the locus coeruleus. Endocrinology 118:1829-1834. CrossRef Medline

Berridge CW, España RA (2000) Synergistic sedative effects of noradrenergic alpha(1)- and beta-receptor blockade on forebrain electroencephalographic and behavioral indices. Neuroscience 99:495-505. CrossRef Medline

Berridge CW, Foote SL (1991) Effects of locus coeruleus activation on electroencephalographic activity in neocortex and hippocampus. J Neurosci 11:3135-3145. Medline

Berridge CW, Waterhouse BD (2003) The locus coeruleus-noradrenergic system: modulation of behavioral state and state-dependent cognitive processes. Brain Res Brain Res Rev 42:33-84. CrossRef Medline

Branchereau P, Van Bockstaele EJ, Chan J, Pickel VM (1996) Pyramidal neurons in rat prefrontal cortex show a complex synaptic response to single electrical stimulation of the locus coeruleus region: evidence for antidromic activation and GABAergic inhibition using in vivo intracellular recording and electron microscopy. Synapse 22:313-331. CrossRef Medline

Carmignoto G, Gomez-Gonzalo M (2010) The contribution of astrocyte signalling to neurovascular coupling. Brain Res Rev 63:138-148. CrossRef Medline

Carter ME, Yizhar O, Chikahisa S, Nguyen H, Adamantidis A, Nishino S, Deisseroth K, de Lecea L (2010) Tuning arousal with optogenetic modulation of locus coeruleus neurons. Nat Neurosci 13:1526-1533. CrossRef Medline

Cauli B, Hamel E (2010) Revisiting the role of neurons in neurovascular coupling. Front Neuroenergetics 2:9. CrossRef Medline

Cauli B, Tong XK, Rancillac A, Serluca N, Lambolez B, Rossier J, Hamel E (2004) Cortical GABA interneurons in neurovascular coupling: relays for subcortical vasoactive pathways. J Neurosci 24:8940-8949. CrossRef Medline

Chida K, Kawamura H, Hatano M (1983) Participation of the nucleus locus coeruleus in DOCA-salt hypertensive rats. Brain Res 273:53-58. CrossRef Medline

Cirelli C, Tononi G (2000) On the functional significance of c-fos induction during the sleep-waking cycle. Sleep 23:453-469. Medline 
Cohen Z, Molinatti G, Hamel E (1997) Astroglial and vascular interactions of noradrenaline terminals in the rat cerebral cortex. J Cereb Blood Flow Metab 17:894-904. CrossRef Medline

de la Torre JC (1976) Evidence for central innervation of intracerebral blood vessels: local cerebral blood flow measurements and histofluorescence analysis by the sucrose-phosphate-glyoxylic acid (SPG) method. Neuroscience 1:455-457. CrossRef Medline

Devilbiss DM, Waterhouse BD (2000) Norepinephrine exhibits two distinct profiles of action on sensory cortical neuron responses to excitatory synaptic stimuli. Synapse 37:273-282. CrossRef Medline

Devilbiss DM, Waterhouse BD (2004) The effects of tonic locus ceruleus output on sensory-evoked responses of ventral posterior medial thalamic and barrel field cortical neurons in the awake rat. J Neurosci 24:1077310785. CrossRef Medline

Devilbiss DM, Waterhouse BD (2011) Phasic and tonic patterns of locus coeruleus output differentially modulate sensory network function in the awake rat. J Neurophysiol 105:69-87. CrossRef Medline

Devonshire IM, Papadakis NG, Port M, Berwick J, Kennerley AJ, Mayhew JE, Overton PG (2012) Neurovascular coupling is brain region-dependent. Neuroimage 59:1997-2006. CrossRef Medline

Dinh L, Nguyen T, Salgado H, Atzori M (2009) Norepinephrine homogeneously inhibits alpha-amino-3-hydroxyl-5-methyl-4-isoxazole-propionate- (AMPAR-) mediated currents in all layers of the temporal cortex of the rat. Neurochem Res 34:1896-1906. CrossRef Medline

Drolet G, Gauthier P (1985) Peripheral and central mechanisms of the pressor response elicited by stimulation of the locus coeruleus in the rat. Can J Physiol Pharmacol 63:599-605. CrossRef Medline

Dunn KM, Nelson MT (2010) Potassium channels and neurovascular coupling. Circ J 74:608-616. CrossRef Medline

Edvinsson L, Hardebo JE, MacKenzie ET, Owman C (1978) Effect of exogenous noradrenaline on local cerebral blood flow after osmotic opening of the blood-brain barrier in the rat. J Physiol 274:149-156. Medline

Farr H, David T (2011) Models of neurovascular coupling via potassium and EET signalling. J Theor Biol 286:13-23. CrossRef Medline

Fields RD, Eshete F, Stevens B, Itoh K (1997) Action potential-dependent regulation of gene expression: temporal specificity in $\mathrm{Ca}^{2+}$, cAMPresponsive element binding proteins, and mitogen-activated protein kinase signaling. J Neurosci 17:7252-7266. Medline

Figley CR, Stroman PW (2011) The role(s) of astrocytes and astrocyte activity in neurometabolism, neurovascular coupling, and the production of functional neuroimaging signals. Eur J Neurosci 33:577-588. CrossRef Medline

Filosa JA, Bonev AD, Straub SV, Meredith AL, Wilkerson MK, Aldrich RW, Nelson MT (2006) Local potassium signaling couples neuronal activity to vasodilation in the brain. Nat Neurosci 9:1397-1403. CrossRef Medline

Florin-Lechner SM, Druhan JP, Aston-Jones G, Valentino RJ (1996) Enhanced norepinephrine release in prefrontal cortex with burst stimulation of the locus coeruleus. Brain Res 742:89-97. CrossRef Medline

Foote SL, Aston-Jones G, Bloom FE (1980) Impulse activity of locus coeruleus neurons in awake rats and monkeys is a function of sensory stimulation and arousal. Proc Natl Acad Sci U S A 77:3033-3037. CrossRef Medline

Foote SL, Bloom FE, Aston-Jones G (1983) Nucleus locus ceruleus: new evidence of anatomical and physiological specificity. Physiol Rev 63:844914. Medline

Fritschy JM, Grzanna R (1989) Immunohistochemical analysis of the neurotoxic effects of DSP-4 identifies two populations of noradrenergic axon terminals. Neuroscience 30:181-197. CrossRef Medline

Fuxe K, Dahlström AB, Jonsson G, Marcellino D, Guescini M, Dam M, Manger P, Agnati L (2010) The discovery of central monoamine neurons gave volume transmission to the wired brain. Prog Neurobiol 90:82-100. CrossRef Medline

Girouard H, Bonev AD, Hannah RM, Meredith A, Aldrich RW, Nelson MT (2010) Astrocytic endfoot $\mathrm{Ca}^{2+}$ and BK channels determine both arteriolar dilation and constriction. Proc Natl Acad Sci U S A 107:3811-3816. CrossRef Medline

Goadsby PJ, Duckworth JW (1989) Low frequency stimulation of the locus coeruleus reduces regional cerebral blood flow in the spinalized cat. Brain Res 476:71-77. CrossRef Medline

Gonchar Y, Burkhalter A (1997) Three distinct families of GABAergic neurons in rat visual cortex. Cereb Cortex 7:347-358. CrossRef Medline

Häggendal E, Johansson B (1965) Effects of arterial carbon dioxide tension and oxygen saturation on cerebral blood flow autoregulation in dogs. Acta Physiol Scand Suppl 258:27-53. Medline

Hamel E (2006) Perivascular nerves and the regulation of cerebrovascular tone. J Appl Physiol 100:1059-1064. CrossRef Medline

Harder DR, Alkayed NJ, Lange AR, Gebremedhin D, Roman RJ (1998) Functional hyperemia in the brain: hypothesis for astrocyte-derived vasodilator metabolites. Stroke 29:229-234. CrossRef Medline

Harper AM (1966) Autoregulation of cerebral blood flow: influence of the arterial blood pressure on the blood flow through the cerebral cortex. J Neurol Neurosurg Psychiatry 29:398-403. CrossRef Medline

Hartman BK, Zide D, Udenfriend S (1972) The use of dopamine-hydroxylase as a marker for the central noradrenergic nervous system in rat brain. Proc Natl Acad Sci U S A 69:2722-2726. CrossRef Medline

Hertz L, Lovatt D, Goldman SA, Nedergaard M (2010) Adrenoceptors in brain: cellular gene expression and effects on astrocytic metabolism and $\left[\mathrm{Ca}^{2+}\right]_{\mathrm{i}}$. Neurochem Int 57:411-420. CrossRef Medline

Higashimori H, Blanco VM, Tuniki VR, Falck JR, Filosa JA (2010) Role of epoxyeicosatrienoic acids as autocrine metabolites in glutamatemediated $\mathrm{K}^{+}$signaling in perivascular astrocytes. Am J Physiol Cell Physiol 299:C1068-C1078. CrossRef Medline

Jaim-Etcheverry G, Zieher LM (1980) DSP-4: a novel compound with neurotoxic effects on noradrenergic neurons of adult and developing rats. Brain Res 188:513-523. CrossRef Medline

Ji XH, Cao XH, Zhang CL, Feng ZJ, Zhang XH, Ma L, Li BM (2008) Pre-and postsynaptic beta-adrenergic activation enhances excitatory synaptic transmission in layer V/VI pyramidal neurons of the medial prefrontal cortex of rats. Cereb Cortex 18:1506-1520. CrossRef Medline

Jones BE, Moore RY (1974) Catecholamine-containing neurons of the nucleus locus coeruleus in the cat. J Comp Neurol 157:43-51. CrossRef Medline

Jones BE, Moore RY (1977) Ascending projections of the locus coeruleus in the rat. II. Autoradiographic study. Brain Res 127:25-53. Medline

Jonsson G, Hallman H, Ponzio F, Ross S (1981) DSP4 (N-(2-chloroethyl)$\mathrm{N}$-ethyl-2-bromobenzylamine) - a useful denervation tool for central and peripheral noradrenaline neurons. Eur J Pharmacol 72:173-188. CrossRef Medline

Kaufmann WE, Worley PF, Pegg J, Bremer M, Isakson P (1996) COX-2, a synaptically induced enzyme, is expressed by excitatory neurons at postsynaptic sites in rat cerebral cortex. Proc Natl Acad Sci U S A 93:23172321. CrossRef Medline

Kawaguchi Y, Shindou T (1998) Noradrenergic excitation and inhibition of GABAergic cell types in rat frontal cortex. J Neurosci 18:6963-6976. Medline

Kayama Y, Negi T, Sugitani M, Iwama K (1982) Effects of locus coeruleus stimulation on neuronal activities of dorsal lateral geniculate nucleus and perigeniculate reticular nucleus of the rat. Neuroscience 7:655-666. CrossRef Medline

Kissen I, Weiss HR (1991) Effect of peripheral and central alphaadrenoceptor blockade on cerebral microvascular and blood flow responses to hypoxia. Life Sci 48:1351-1363. CrossRef Medline

Kobayashi M, Sasabe T, Shiohama Y, Koshikawa N (2008) Activation of alpha1-adrenoceptors increases firing frequency through protein kinase C in pyramidal neurons of rat visual cortex. Neurosci Lett 430:175-180. CrossRef Medline

Kocharyan A, Fernandes P, Tong XK, Vaucher E, Hamel E (2008) Specific subtypes of cortical GABA interneurons contribute to the neurovascular coupling response to basal forebrain stimulation. J Cereb Blood Flow Metab 28:221-231. CrossRef Medline

Koehler RC, Roman RJ, Harder DR (2009) Astrocytes and the regulation of cerebral blood flow. Trends Neurosci 32:160-169. CrossRef Medline

Kubota Y, Hattori R, Yui Y (1994) Three distinct subpopulations of GABAergic neurons in rat frontal agranular cortex. Brain Res 649:159-173. CrossRef Medline

Lecrux C, Toussay X, Kocharyan A, Fernandes P, Neupane S, Lévesque M, Plaisier F, Shmuel A, Cauli B, Hamel E (2011) Pyramidal neurons are "neurogenic hubs" in the neurovascular coupling response to whisker stimulation. J Neurosci 31:9836-9847. CrossRef Medline

Lecrux C, Kocharyan A, Sandoe CH, Tong XK, Hamel E (2012) Pyramidal cells and cytochrome P450 epoxygenase products in the neurovascular coupling response to basal forebrain cholinergic input. J Cereb Blood Flow Metab 32:896-906. CrossRef Medline

Leithner C, Royl G, Offenhauser N, Füchtemeier M, Kohl-Bareis M, 
Villringer A, Dirnagl U, Lindauer U (2010) Pharmacological uncoupling of activation induced increases in $\mathrm{CBF}$ and $\mathrm{CMRO} 2$. J Cereb Blood Flow Metab 30:311-322. CrossRef Medline

Lindauer U, Megow D, Matsuda H, Dirnagl U (1999) Nitric oxide: a modulator, but not a mediator, of neurovascular coupling in rat somatosensory cortex. Am J Physiol 277:H799-H811. Medline

Liu X, Li C, Falck JR, Roman RJ, Harder DR, Koehler RC (2008) Interaction of nitric oxide, 20-HETE, and EETs during functional hyperemia in whisker barrel cortex. Am J Physiol Heart Circ Physiol 295:H619-H631. CrossRef Medline

MacKenzie ET, McCulloch J, Harper AM (1976a) Influence of endogenous norepinephrine on cerebral blood flow and metabolism. Am J Physiol 231:489-494. Medline

MacKenzie ET, McCulloch J, O’Kean M, Pickard JD, Harper AM (1976b) Cerebral circulation and norepinephrine: relevance of the blood-brain barrier. Am J Physiol 231:483-488. Medline

Mraovitch S, Iadecola C, Ruggiero DA, Reis DJ (1985) Widespread reductions in cerebral blood flow and metabolism elicited by electrical stimulation of the parabrachial nucleus in rat. Brain Res 341:283-296. CrossRef Medline

Nicholas AP, Hökfelt T, Pieribone VA (1996) The distribution and significance of CNS adrenoceptors examined with in situ hybridization. Trends Pharmacol sci 17:245-255. CrossRef Medline

Nishihara M, Yokotani K, Inoue S, Osumi Y (2000) U-46619, a selective thromboxane A2 mimetic, inhibits the release of endogenous noradrenaline from the rat hippocampus in vitro. Jpn J Pharmacol 82:226-231. CrossRef Medline

Niwa K, Araki E, Morham SG, Ross ME, Iadecola C (2000) Cyclooxygenase-2 contributes to functional hyperemia in whisker-barrel cortex. J Neurosci 20: 763-770. Medline

Nowicky AV, Christofi G, Bindman LJ (1992) Investigation of betaadrenergic modulation of synaptic transmission and postsynaptic induction of associative LTP in layer V neurones in slices of rat sensorimotor cortex. Neurosci Lett 137:270-273. CrossRef Medline

Papadopoulos GC, Parnavelas JG, Buijs RM (1989) Light and electron microscopic immunocytochemical analysis of the noradrenaline innervation of the rat visual cortex. J Neurocytol 18:1-10. CrossRef Medline

Paspalas CD, Papadopoulos GC (1996) Ultrastructural relationships between noradrenergic nerve fibers and non-neuronal elements in the rat cerebral cortex. Glia 17:133-146. CrossRef Medline

Paspalas CD, Papadopoulos GC (1999) Noradrenergic innervation of peptidergic interneurons in the rat visual cortex. Cereb Cortex 9:844-853. CrossRef Medline

Petzold GC, Murthy VN (2011) Role of astrocytes in neurovascular coupling. Neuron 71:782-797. CrossRef Medline

Raichle ME, Hartman BK, Eichling JO, Sharpe LG (1975) Central noradrenergic regulation of cerebral blood flow and vascular permeability. Proc Natl Acad Sci U S A 72:3726-3730. CrossRef Medline

Rodrigo J, Fernández P, Bentura ML, de Velasco JM, Serrano J, Uttenthal O, Martínez-Murillo R (1998) Distribution of catecholaminergic afferent fibres in the rat globus pallidus and their relations with cholinergic neurons. J Chem Neuroanat 15:1-20. CrossRef Medline

Salgado H, Garcia-Oscos F, Patel A, Martinolich L, Nichols JA, Dinh L, Roychowdhury S, Tseng KY, Atzori M (2011) Layer-specific noradrenergic modulation of inhibition in cortical layer II/III. Cereb Cortex 21:212-221. CrossRef Medline

Salgado H, Garcia-Oscos F, Martinolich L, Hall S, Restom R, Tseng KY, Atzori M (2012) Pre- and postsynaptic effects of norepinephrine on gamma- aminobutyric acid-mediated synaptic transmission in layer $2 / 3$ of the rat auditory cortex. Synapse 66:20-28. CrossRef Medline

Sato H, Kayama Y (1983) Effects of noradrenaline applied iontophoretically on rat superior collicular neurons. Brain Res Bull 10:453-457. CrossRef Medline

Sato H, Fox K, Daw NW (1989) Effect of electrical stimulation of locus coeruleus on the activity of neurons in the cat visual cortex. J Neurophysiol 62:946-958. Medline

Schäfer K, Blankenburg F, Kupers R, Grüner JM, Law I, Lauritzen M, Larsson HB (2012) Negative BOLD signal changes in ipsilateral primary somatosensory cortex are associated with perfusion decreases and behavioral evidence for functional inhibition. Neuroimage 59:3119-3127. CrossRef Medline

Segev I (2006) What do dendrites and their synapses tell the neuron? J Neurophysiol 95:1295-1297. CrossRef Medline

Séguéla P, Watkins KC, Geffard M, Descarries L (1990) Noradrenaline axon terminals in adult rat neocortex: an immunocytochemical analysis in serial thin sections. Neuroscience 35:249-264. CrossRef Medline

Shmuel A, Augath M, Oeltermann A, Logothetis NK (2006) Negative functional MRI response correlates with decreases in neuronal activity in monkey visual area V1. Nat Neurosci 9:569-577. CrossRef Medline

Sirotin YB, Das A (2009) Anticipatory haemodynamic signals in sensory cortex not predicted by local neuronal activity. Nature 457:475-479. CrossRef Medline

Sokrab TE, Johansson BB (1989) Regional cerebral blood flow in acute hypertension induced by adrenaline, noradrenaline and phenylephrine in the conscious rat. Acta Physiol Scand 137:101-106. CrossRef Medline

Sorg O, Magistretti PJ (1991) Characterization of the glycogenolysis elicited by vasoactive intestinal peptide, noradrenaline and adenosine in primary cultures of mouse cerebral cortical astrocytes. Brain Res 563:227-233. CrossRef Medline

Stefanovic B, Bosetti F, Silva AC (2006) Modulatory role of cyclooxygenase-2 in cerebrovascular coupling. Neuroimage 32:23-32. CrossRef Medline

Stone EA, Zhang Y, John S, Filer D, Bing G (1993) Effect of locus coeruleus lesion on c-fos expression in the cerebral cortex caused by yohimbine injection or stress. Brain Res 603:181-185. CrossRef Medline

Stone EA, Zhang Y, Carr KD (1995) Massive activation of c-fos in forebrain after mechanical stimulation of the locus coeruleus. Brain Res Bull 36:77-80. CrossRef Medline

Usui H, Kurahashi K, Shirahase H, Fukui K, Fujiwara M (1987) Endothelium-dependent vasocontraction in response to noradrenaline in the canine cerebral artery. Jpn J Pharmacol 44:228-231. CrossRef Medline

Vaucher E, Tong XK, Cholet N, Lantin S, Hamel E (2000) GABA neurons provide a rich input to microvessels but not nitric oxide neurons in the rat cerebral cortex: a means for direct regulation of local cerebral blood flow. J Comp Neurol 421:161-171. CrossRef Medline

Wang H, Hitron IM, Iadecola C, Pickel VM (2005) Synaptic and vascular associations of neurons containing cyclooxygenase-2 and nitric oxide synthase in rat somatosensory cortex. Cereb Cortex 15:1250-1260. CrossRef Medline

Waterhouse BD, Moises HC, Woodward DJ (1998) Phasic activation of the locus coeruleus enhances responses of primary sensory cortical neurons to peripheral receptive field stimulation. Brain Res 790:33-44. CrossRef Medline

Zielke HR, Zielke CL, Baab PJ, Tildon JT (2007) Effect of fluorocitrate on cerebral oxidation of lactate and glucose in freely moving rats. J Neurochem 101:9-16. CrossRef Medline 